\title{
A rare variant of common arterial trunk
}

\author{
JEAN E RUBAY, FERGUS J MACARTNEY, ROBERT H ANDERSON* \\ From the Thoracic Unit, The Hospital for Sick Children, London and ${ }^{\star}$ Department of Paediatrics, \\ Cardiothoracic Institute, Brompton Hospital, London
}

SUMMARY A 13 day old baby was admitted to hospital with multiple abnormalities, increasing or cyanosis, and cardiac failure. Cardiac catheterisation was performed on the day of admission and iv he died shortly after the procedure. A rare variant of common arterial trunk, in which the pul-i monary arteries arose directly from the underside of the aortic arch, was found at necropsy.

A common arterial trunk is defined as that condition in which a single arterial trunk leaves the heart through a single arterial valve and supplies the aorta, one or both pulmonary arteries, and the coronary arteries. ${ }^{1}$ We have recently seen a case, unique to the best of our knowledge, in which the pulmonary arteries arose directly from the underside of the aortic arch. This variant is not accounted for in the classic categorisation of Collett and Edwards. ${ }^{2}$

\section{Case report}

\section{CLINICAL FINDINGS}

A $2.8 \mathrm{~kg}$ male baby was admitted to the intensive care unit at the age of 13 days because of increasing cyanosis and cardiac failure. The mother had been in contact with a rubella case at five months' gestation. After caesarean delivery the baby's Apgar scores were 7 and 9 at one and five minutes respectively. Multiple anomalies were noted, including a cleft lip, a short neck with webbing, a low posterior hairline, low set ears, and a very small penis. A systolic murmur was heard on examination of the cardiovascular system. He became cyanosed at the age of three days and went into cardiac failure during the first week. He was then transferred for more detailed cardiac investigations. Examination disclosed a cyanosed baby with an increased respiratory rate of 90 per minute, and a pulse rate of 150 beats/minute, femoral pulses that were variable in intensity, and an active heart with a loud ejection click with a grade (4/6) ejection systolic murmur best heard at the left

Requests for reprints to Professor Robert H Anderson, Department of Paediatrics, Cardiothoracic Institute, Brompton Hospital, Fulham Road, London SW3 6HP. sternal border. The second heart sound was single and the blood pressure was $80 / 50 \mathrm{~mm} \mathrm{Hg}$. The liver? was palpable $3 \mathrm{~cm}$ below the costal margin.

Chest radiography showed mild cardiomegaly $\cong$ with increased pulmonary vascular markings. Car-diac catheterisation showed a large left to right shunto at the atrial level and a considerable increase in both ventricular end diastolic pressures. Angiocardiography revealed a common arterial trunk with $\frac{2}{\mathbb{D}}$ ventricular septal defect and markedly impaired ventricular function. The pulmonary arteries were $\vec{\circ}$ noted to originate from the underside of the aortic ${ }^{3}$ arch (fig 1a). The baby remained in a poor condition and after angiocardiography a severe progressive bradycardia developed. All attempts at resuscitation were unsuccessful.

At necropsy the heart showed the usual atrialo arrangement (situs solitus). The right atrium 3 . received the inferior systemic return. The right 0 superior caval vein was absent, the superior venous $₹$ drainage returning through a left superior caval vein $\bigcirc$ that drained through the coronary sinus. There was $D$ a secundum atrial septal defect. The four pulmonary을. veins were connected to the left atrium. A solitary N trunk arose exclusively from the right ventricle (fig 2). There was a ventricular septal defect in a sub- 0 arterial position with fibrous continuity between the $\omega$ arterial valve and both atrioventricular valves. The left atrium and left ventricle were small, but wereo connected by a normally positioned mitral valve. The solitary arterial trunk gave rise to both coronary? arteries and, from its superior aspect, to the innominate, the left common carotid, and the left sub- $\frac{}{D}$ clavian arteries. Both pulmonary arteries originated directly from the underside of the aortic arch (fig:. 1b). No other sources of pulmonary blood supply? were present. 

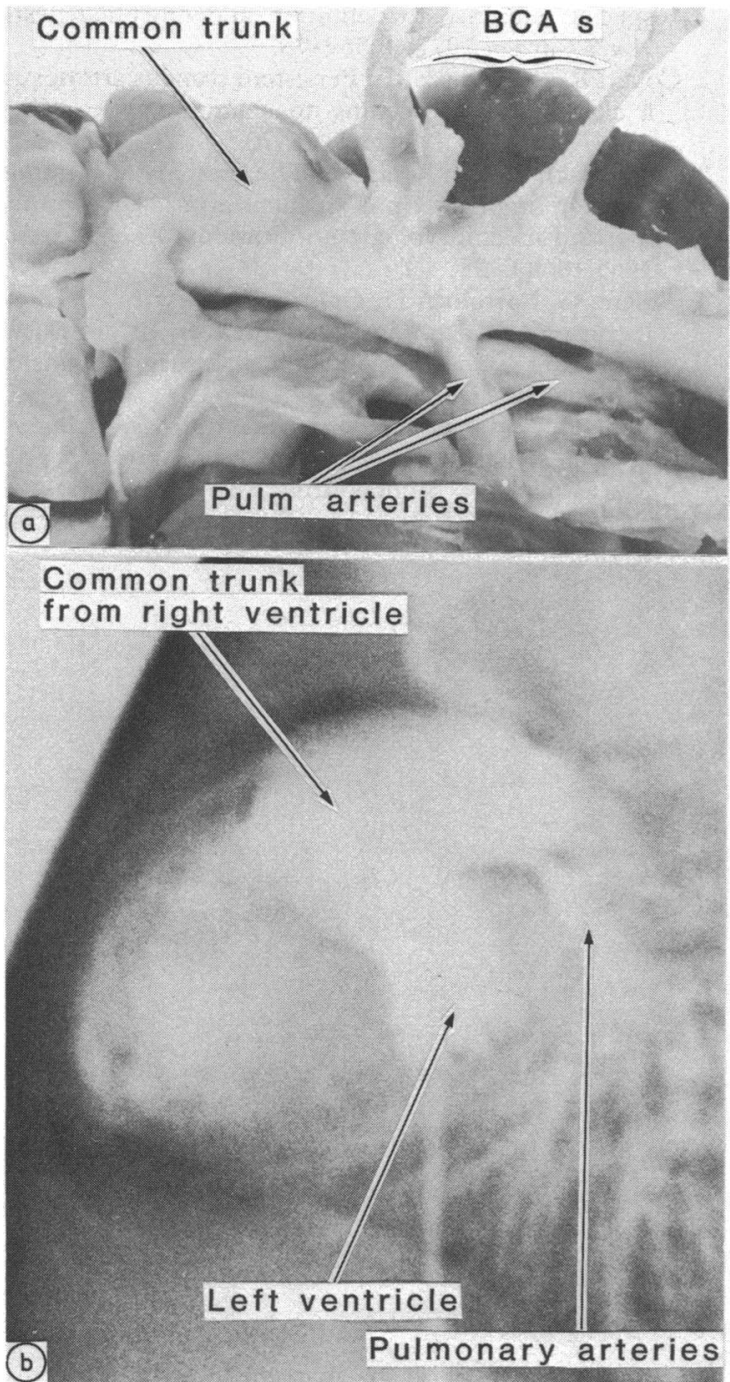

Fig 1 (a) Photograph of the aortic arch at necropsy. Note that the pulmonary arteries originate from the underside of the aorta opposite a point between the left carotid and subclavian arteries. BCAs, brachiocephalic arteries.

(b) Lateral projection of a selective left ventriculogram.

\section{Discussion}

The present case does not fit easily into conventional categorisations of common aortopulmonary trunk (truncus arteriosus communis). Though some would hold that a common arterial trunk can exist with two arterial valves, ${ }^{3}$ we prefer to define this entity as a solitary arterial trunk guarded by a common arterial valve and directly supplying the coronary arteries, at least one pulmonary artery, and the systemic arteries. ${ }^{1}$ Almost always the common trunk

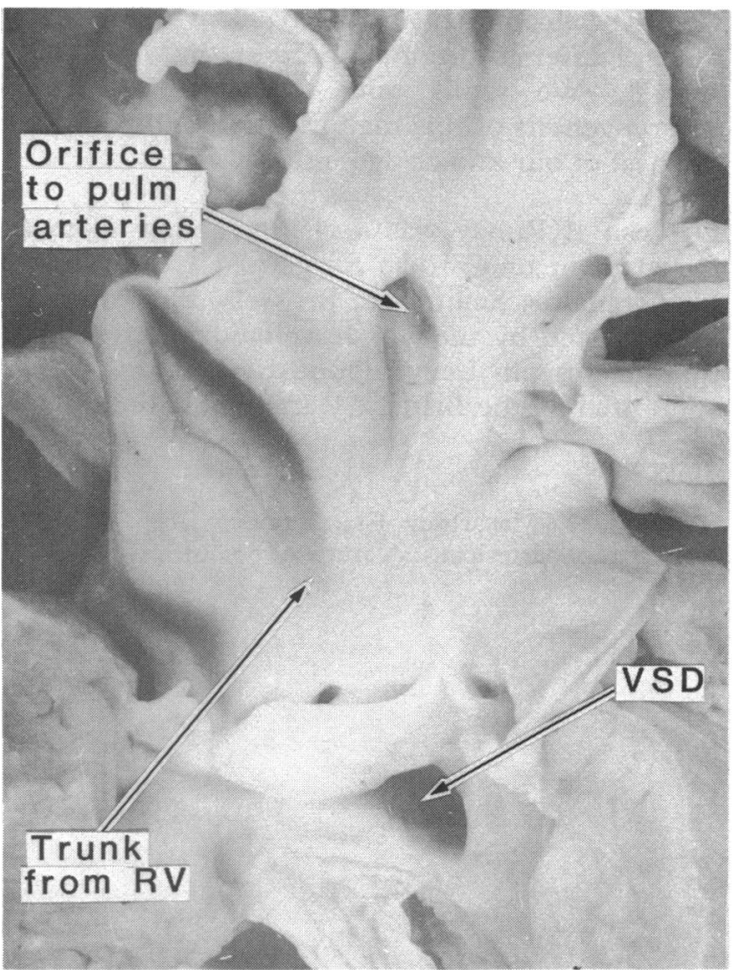

Fig 2 Internal view of the ascending aorta and arch. Note the common origin of the pulmonary arteries.

in this condition overrides the ventricular septum.

The first unusual feature of this case was the origin of the trunk entirely from the right ventricle. This rare variant has been well described. ${ }^{14}$ The second distinctive feature was the site of origin of the pulmonary arteries. This feature was the basis of Collett and Edwards's well known classification. ${ }^{2}$ According to these workers, in types I to III the pulmonary arteries arise from the ascending trunk, exhibiting a short common segment in type I, adjacent but separate origins in type II, and lateralised origins in type III. Their type IV is best described as a solitary arterial trunk, since in the absence of central pulmonary arteries (the intrapulmonary arteries being supplied by major collaterals) it is impossible to say whether the trunk is a common trunk or an aorta. ${ }^{5}$

The present case fits none of these categories. There are confluent central pulmonary arteries, but they arise from the arch between the left carotid and left subclavian arteries. They did not arise via an arterial duct, a persistent fifth aortic arch, nor from systemic/pulmonary collateral arteries. One might, with tongue in cheek, describe this case as "type III and a half", but in our view a better description 
would be "common arterial trunk with both pulmonary arteries originating from the arch of the aorta". We will not speculate upon the embryogenesis of this malformation. The case is to the best of our knowledge unique.

Dr Jean E Rubay was a visiting fellow from the Department of Cardiac Surgery, UCL, Cliniques Universitaires Saint-Luc, Brussels, Belgium. FJM is supported by the Vandervell Foundation; RHA by the Joseph Levy Foundation, and both are supported by the British Heart Foundation.

\section{References}

1 Crupi G, Macartney FJ, Anderson RH. Persistent truncus arteriosus. A study of 66 autopsy cases with special reference to definition and morphogenesis. Am $\mathcal{F}$ Cardiol 1977;40:569-78.

2 Collett RW, Edwards JE. Persistent truncus arteriosus? a classification according to anatomic types. Surg Clin North Am 1949;29:1245-70.

3 Van Praagh R, Van Praagh S. The anatomy of commo aorticopulmonary trunk (truncus arteriosus commue nis) and its embryologic implications. Am $\mathcal{f}$ Cardiog 1965;16:406-25.

4 Thiene G, Bortolotti U, Gallucci V, Terribile V, Pel $\vec{P}$ legrino PA. Anatomical study of truncus arteriosus. communis with embryological and surgical consid erations. Br Heart $\mathcal{F}$ 1976;38:1109-23.

5 Thiene G, Anderson RH. Pulmonary atresia with ven tricular septal defect. Anatomy. In: Anderson RHN Macartney FJ, Shinebourne EA, Tynan M, eds N Paediatric cardiology 5. Edinburgh: Churchilis Livingstone, 1983:80-101. 